\title{
Cholinesterase inhibitors and memantine for Parkinson's disease dementia and Lewy body dementia: A meta-analysis
}

\author{
YAN-HONG MENG ${ }^{1,2}$, PAN-PAN WANG ${ }^{1,2}$, YA-XUE SONG ${ }^{2,3}$ and JIAN-HUA WANG ${ }^{2}$ \\ ${ }^{1}$ Department of Graduate School, Hebei Medical University, Shijiazhuang, Hebei 050017; ${ }^{2}$ Department of Neurology, \\ Hebei General Hospital, Shijiazhuang, Hebei 050051; ${ }^{3}$ Department of Graduate School, \\ Hebei North University, Zhangjiakou, Hebei 075000, P.R. China
}

Received May 31, 2018; Accepted November 30, 2018

DOI: $10.3892 /$ etm.2018.7129

\begin{abstract}
Recently, several randomized controlled trials on the use of cholinesterase inhibitors or memantine as treatments for cognitive impairment in Parkinson's disease (CIND-PD), Parkinson's disease with dementia (PDD) and dementia with Lewy bodies (DLB) were completed. The present study provided a meta-analysis of these studies to evaluate the efficacy of cholinesterase inhibitors and memantine on CIND-PD, PDD and DLB. The Cochrane Library, Pubmed, Embase and Web of Science databases were searched to retrieve eligible studies. As primary efficacy outcomes, cognitive function, global impression, behavioral symptoms and motor function were selected, while falling and adverse events were regarded as safety outcomes. Of note, domain-specific cognitive function was assessed as a primary efficacy outcome and falling as a safety outcome, which, to the best of our knowledge, has not been studied previously in CIND-PD, PDD and DLB. A total of 15 trials were included in the present meta-analysis. The results revealed that treatment with cholinesterase inhibitors resulted in improvements in cognitive function, the clinician's global impression, behavioral symptoms and motor function, in accordance with the results of previous studies. Furthermore, it was revealed that cholinesterase inhibitors had a significant effect on attention, processing speed, executive functions, memory and language; however, they did not improve visuospatial cognition compared with placebos. Memantine had a significant effect on attention, processing speed and executive functions. In addition, cholinesterase inhibitors and memantine did not significantly reduce falling. It was demonstrated that an increased number of adverse events occurred in the pooled cholinesterase inhibitors and memantine group, compared with that in the placebo group
\end{abstract}

Correspondence to: Professor Jian-Hua Wang, Department of Neurology, Hebei General Hospital, 348 West Heping Road, Shijiazhuang, Hebei 050051, P.R. China

E-mail:wangjh6304@sina.com

Key words: cholinesterase inhibitors, memantine, Parkinson's disease, dementia, Lewy body dementia, meta-analysis (risk ratio $(\mathrm{RR})=1.09 ; 95 \%$ confidence interval $(\mathrm{CI})$ : 1.04-1.16; $\mathrm{P}=0.001$ ); however, in the subgroup analysis, only the rivastigmine group experienced significantly more adverse events than the placebo group ( 85 vs. $73 \%$; $R R=1.18$; $95 \%$ CI: $1.08-1.29$; $\mathrm{P}=0.0001$ ), but donepezil and memantine did not produce any significant adverse events. In conclusion, cholinesterase inhibitors and memantine have an effect not only on global cognitive function and motor function, but also on attention, processing speed, executive functions, memory and language. However, careful monitoring of the side effects of rivastigmine may be required. Further clinical trials are required to verify these conclusions.

\section{Introduction}

The most common types of dementia are Alzheimer's dementia (AD) and Parkinson's disease dementia (PDD), while dementia with Lewy bodies (DLB) is the second most common type of dementia, accounting for $15-20 \%$ of the global incidence of dementia (1-3). PDD and DLB are characterized by accumulation of Lewy bodies in brain cells (4). From a clinical and neuropathological perspective, DLB and PDD are similar conditions with the same features, namely dementia, parkinsonism, hallucinations and fluctuations of attention or arousal (5). They may be distinguished on the basis of the relative timing of dementia and Parkinsonism. Several meta-analyses have been performed to examine the efficacy and safety of cholinesterase inhibitors and memantine, or each drug separately, on CIND-PD, PDD and DLB (6-9). The studies reported that cholinesterase inhibitors and memantine improve the global impression, cognitive function, psychiatric symptoms or motor function. They evaluated cognitive function via the use of certain screening tests, including the Mini Mental State Examination (MMSE) and Montreal Cognitive Assessment (MoCA). To the best of our knowledge, no previous meta-analysis has focused on cognitive domains, including attention, processing speed, executive functions, memory and language. The present study hypothesized that cholinesterase inhibitors and memantine may also improve the patients' cognitive domains in addition to global cognitive function, which may further prove their efficacy. In addition, falls are a common and severe complication of PD patients and seriously affect their daily safety, prognosis and quality 
of life (10), and thus, the effect of cholinesterase inhibitors and memantine on falls was also investigated.

\section{Materials and methods}

Search strategy. The Cochrane Library, as well as the Pubmed, Embase and Web of Science databases, were searched for relevant studies on clinical trials on cognitive impairment in Parkinson's disease (CIND-PD), PDD or DLB published before July 2018. The search terms were as follows: ('Lewy Body Disease' OR 'DLB' OR 'LBD' OR 'dementia with Lewy bod*' OR 'Lewy bodies dementia' OR 'Lewy Bodies' OR 'lewy* bod*') and \{'Parkinson Disease' OR 'parkinson* disease dement*' OR 'PDD' OR ['cognit*' and ('PD' or 'parkinson*')] OR 'PD-CIND' OR ('CIND' and 'parkinson*')\} and ['Cholinesterase Inhibitors' OR 'cholinesterase inhibitor*' OR 'Galantamine' OR 'galantamine' OR 'galanthamine' OR ('reminyl*' or 'Nivalin*' or 'Razadyne*') OR 'donepezil' OR ('Aricept*' or 'E2020') OR 'rivastigmine' OR ('Exelon*' or 'SDZ ENA 713') OR ('Memantine' OR 'Namenda' OR 'Ebixa' OR 'Mntine')].

Selection criteria. Randomized, placebo-controlled trials that assessed the efficacy of cholinesterase inhibitors in patients with CIND-PD, DLB and PDD were selected for the present meta-analysis. The inclusion criteria were as follows: Patients with PD were included if they fulfilled the UK PD Society Brain Bank clinical diagnostic criteria for PD or clinically definite and probable PD diagnosis (11-14), and if they subsequently developed dementia, met the Diagnostic and Statistical Manual of Mental Disorders fourth edition/revised fourth edition or the Movement Disorders Society criteria at least 1 year after the onset of PD symptoms (15); DLB patients were included if they met the consensus guidelines for the clinical and pathological diagnosis of DLB or revised consensus criteria (16).

Data extraction and quality assessment. Two authors independently selected trials for inclusion in the meta-analysis and extracted information on the study design, patient selection criteria, drug doses, trial durations, primary and secondary outcomes, discontinuations and adverse events in each trial. Disagreements were resolved by discussion with other team members or by contacting the original investigators, who were all sent emails with requests to provide the exact data. For any missing standard deviation data, which were not obtainable from the primary investigators, estimated values calculated using the formula no. 8.5.2.3 in the Cochrane handbook were used in the analysis (17). The Cochrane criteria were used to assess risk of bias (18), and Grades of Recommendation, Assessment, Development and Evaluation (GRADE) Profiler software (version 3.6; Cochrane, London, UK) was used to evaluate the quality of the studies according to the GRADE methods (19).

Statistical analysis. The meta-analysis was performed using RevMan software (version 5.3; Cochrane), employing the inverse variance method. Heterogeneity was assessed using the Chi-squared and $\mathrm{I}^{2}$ statistical tests, and considered significant if $\mathrm{P}<0.05$ and $\mathrm{I}^{2}>50 \%$ was obtained by the former and the latter test, respectively. If $\mathrm{I}^{2}>50 \%$, a sensitivity analysis was performed to determine the reasons for heterogeneity. In this commonly used sensitivity analysis method, each study included is eliminated one by one, followed by effect-size calculation, or the inclusion criteria are changed or certain types of literature are removed prior to effect volume combination. For continuous data, mean differences (MD) or standardized mean differences (SMD) were used in combination with the effect-size (Hedges'g) data. For dichotomous data, the risk ratio (RR) was estimated along with associated $95 \%$ confidence interval (CI). Overall, SMD and RR with 95\% CI were estimated with Mantel-Haenszel fixed-effects (20) or DerSimonian-Laird random-effects models (21). When it was confirmed that there was no heterogeneity, pooled SMD and RR were calculated according to the Mantel-Haenszel fixed-effects model $\left(\mathrm{P}>0.05\right.$ or $\left.\mathrm{I}^{2}<50 \%\right)$. If there was evidence of heterogeneity, pooled SMD and RR were calculated according to the DerSimonian-Laird random-effects model $\left(\mathrm{P}<0.05\right.$ or $\left.\mathrm{I}^{2}>50 \%\right)$. Begg's funnel plots were drawn to evaluate publication bias.

\section{Results}

Study selection and characteristics. A total of 2,135 records of trials for the treatment of PD-CIND, PDD or DLB were retrieved from the Cochrane Library, Pubmed, Embase and Web of Science. Of these studies, a large quantity was not relevant, including studies regarding other diseases or interventions, or duplications. A total of 237 records were considered suitable after screening the titles and abstracts. Finally, of the 237 full-text articles, only 15 trials [six donepezil (22-27), five rivastigmine $(10,28-31)$ and four memantine trials (32-35)] were included in the present meta-analysis. The flow chart for the selection of studies is presented in Fig. 1 and the details of each included article are presented in Table I. The methodological quality of all studies evaluated using the Cochrane risk of bias criteria is provided in Fig. 2.

\section{Efficacy outcomes}

Global cognitive function. Of the trials included, $12(10,22-30,32,33)$ evaluated cognitive function using the MMSE and MoCA (Fig. 3). The standard mean difference in participants who received cholinesterase inhibitors or memantine vs. placebo was 0.46 (95\% CI: 0.36-0.55; P<0.00001), suggesting significant benefits. Regarding different subgroups, benefits were determined for donepezil in DLB $(\mathrm{SMD}=0.63$; 95\% CI: 0.42-0.84; $\mathrm{P}<0.00001)$ and in PDD $(\mathrm{SMD}=0.51$; 95\% CI: 0.36-0.66; $\mathrm{P}<0.00001)$, and for rivastigmine in PDD $(\mathrm{SMD}=0.45 ; 95 \% \mathrm{CI}: 0.28-0.62 ; \mathrm{P}<0.00001)$, but not for rivastigmine in DLB or memantine in either DLB or PDD.

Cognitive domains. A total of seven trials $(23,25-27,29,31,33)$ examined the cognitive domains of attention, processing speed and executive functions (Fig. 4A). The results of the meta-analysis indicated that cholinesterase inhibitors and memantine provided significant benefits compared with placebo (MD $=1.19 ; 95 \% \mathrm{CI}$ : $0.65-1.73 ; \mathrm{P}<0.0001)$. Furthermore, three trials $(23,26,33)$ examined the cognitive domain of memory (Fig. 4B). The meta-analysis revealed that treatment with cholinesterase inhibitors achieved a significant improvement in patients compared with placebo ( $\mathrm{MD}=0.24 ; 95 \% \mathrm{CI}$ : $0.11-0.37 ; \mathrm{P}=0.0003)$. In addition, three trials $(26,29,33)$ examined visuospatial cognition 


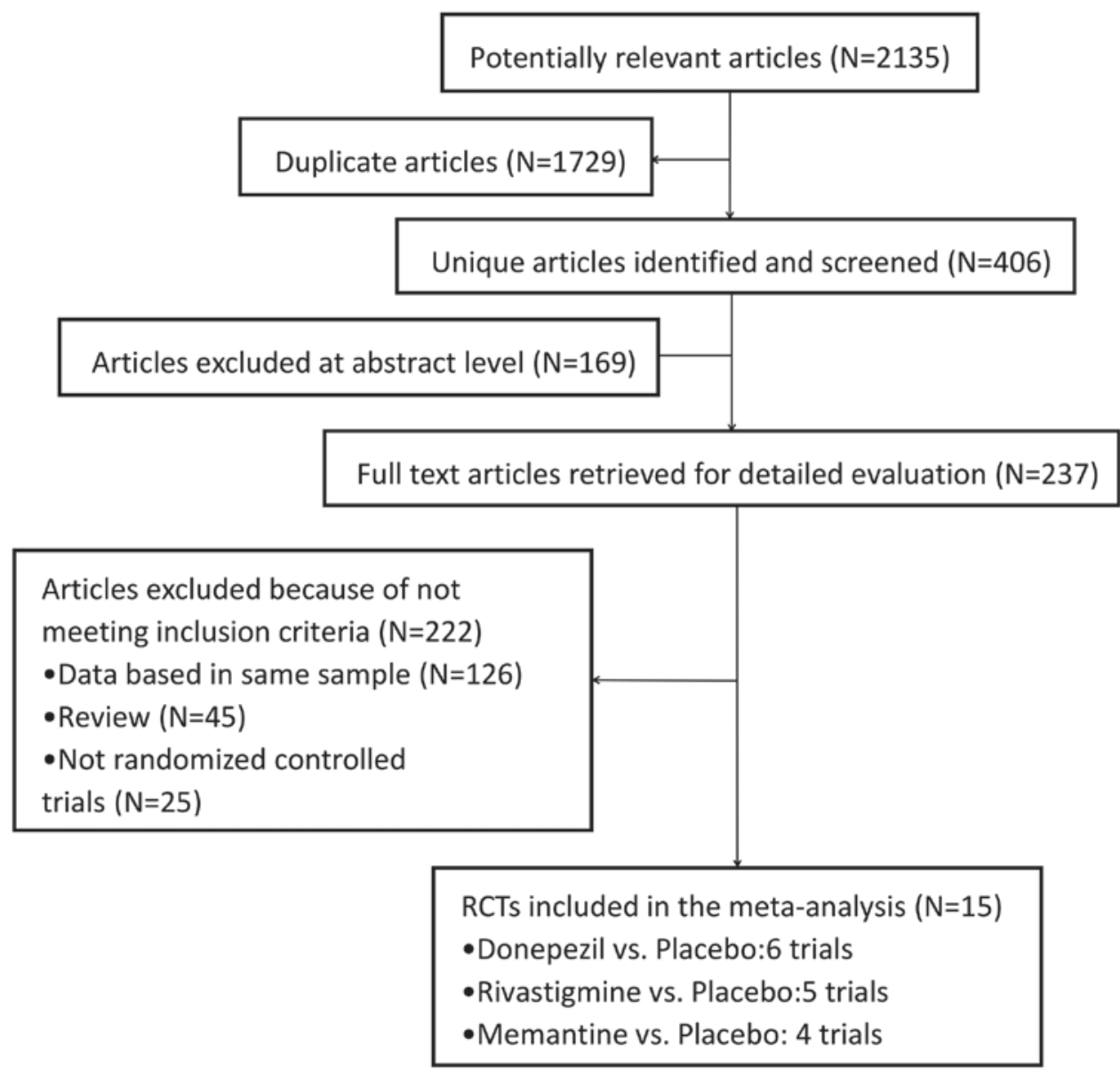

Figure 1. Flow diagram of study selection for the meta-analysis. RCT, randomized controlled trial.

(Fig. 4C). The results indicated that cholinesterase inhibitors did not improve visuospatial function when compared with the placebo (MD=0.13; 95\% CI: $-0.45-0.71 ; \mathrm{P}=0.65)$. Finally, four trials $(23,25,29,33)$ examined the cognitive domain of language (Fig. 4D). The meta-analysis revealed that cholinesterase inhibitors had a significant effect in patients compared with placebo $(\mathrm{MD}=1.44 ; 95 \%$ CI: 0.34-2.53; $\mathrm{P}=0.01)$.

Global impression. A total of seven trials $(23-25,29,32,34,35)$ examined the subjects on the Clinician's Global Impression of Change (CGIC) scale. As indicated in the forest plot in Fig. 5, significant improvements in participants treated with the drugs compared with the placebo were revealed $(\mathrm{RR}=1.29$; 95\% $\mathrm{CI}$ : $1.15-1.45 ; \mathrm{P}<0.0001)$. Furthermore, in the following subgroups, significant benefits compared with the placebo group were identified: DLB treated with donepezil $3 \mathrm{mg}(\mathrm{RR}=2.06$; 95\% CI: 1.18-3.60), donepezil $5 \mathrm{mg}(\mathrm{RR}=2.13$; 95\% CI: 1.22-3.70) and donepezil $10 \mathrm{mg}(\mathrm{RR}=1.93$; 95\% CI: 1.08-3.43); and $\mathrm{PDD}$ treated with rivastigmine $(\mathrm{RR}=1.37$; $95 \% \mathrm{CI}$ : 1.05-1.79). However, no significant benefits were determined for donepezil in PDD, memantine in PDD and DLB.

Behavioral symptoms. Altered Neuropsychiatric Inventory (NPI) scores were determined by nine trials $(22,23,25,26,28$, 29,31,32,34). As presented in Fig. 6, meta-analysis revealed a significant effect on NPI-10 among all studies [MD=-1.73; 95\% CI: -(2.84-0.62); $\mathrm{P}=0.002]$.
Motor function. A total of 10 trials assessed motor function (10,22-24,26,27,30-32,34). Compared with the placebo, patients treated with cholinesterase inhibitors and memantine exhibited improvements in motor function (Fig. 7). The results of the meta-analysis suggested a significant effect on patients treated with drugs compared with placebo $[\mathrm{MD}=-1.38$; 95\% CI: -(1.96-0.79); $\mathrm{P}<0.00001]$. However, only rivastigmine in PDD provided a significant benefit $[\mathrm{MD}=-2.32$; 95\% CI: -(3.09-1.55); $\mathrm{P}<0.00001]$, while donepezil in PDD or DLB, rivastigmine in DLB, and memantine in PDD and/or DLB did not. Furthermore, a subgroup analysis revealed that the dose of donepezil had no significant effect in improving DLB.

Falling. A considerable number of patients experience falls as a complication of PDD and five of the trials included $(10,25,29,32,35)$ reported on the quantity of falling. As presented in Fig. 8, the meta-analysis revealed that cholinesterase inhibitors and memantine did not significantly reduce falling compared with the placebo $(\mathrm{RR}=0.74 ; 95 \% \mathrm{CI}$ : 0.51-1.08; $\mathrm{P}=0.12$ ), thereby demonstrating that treatment with the drugs did not significantly prevent falls.

Adverse events. Adverse events were inconsistently mentioned and reported by 13 trials (10,22-28,30-32,34,35). The common adverse events were cholinergic in nature (nausea, vomiting), aggravation of Parkinson and psychiatric symptoms (tremor, 


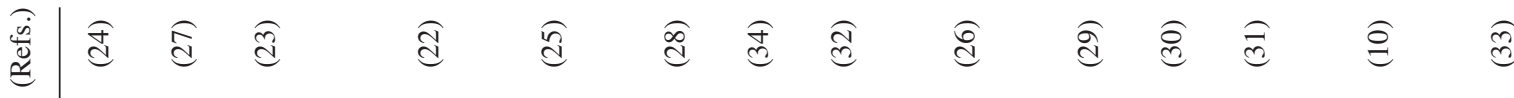

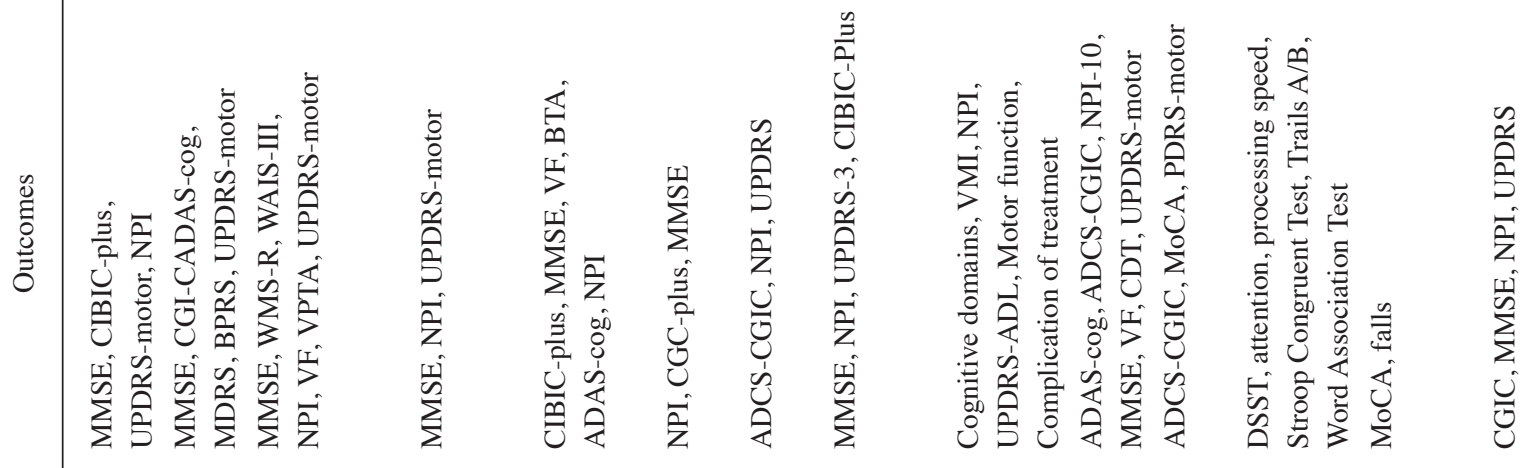

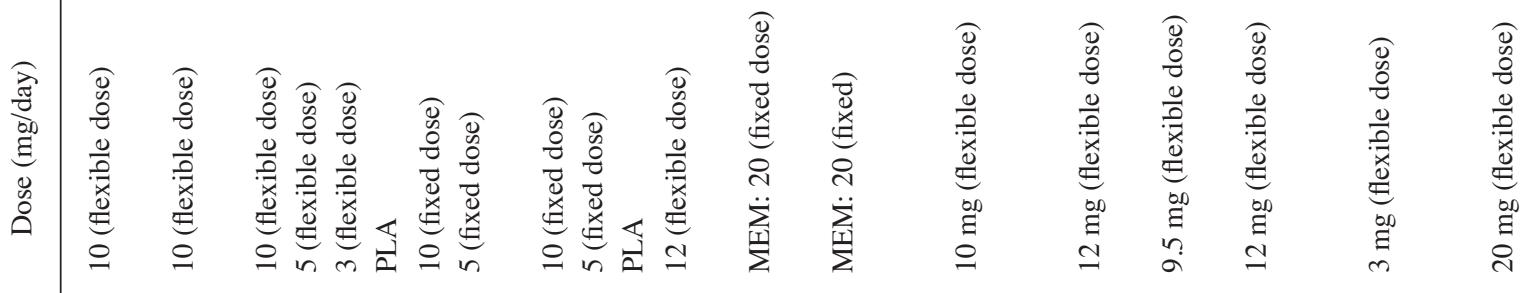

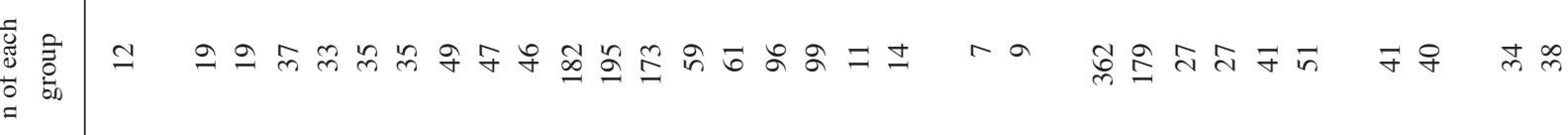

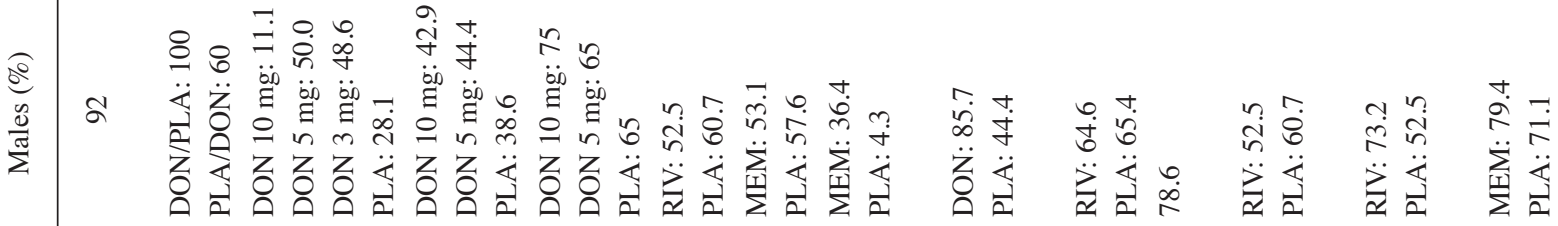

क人

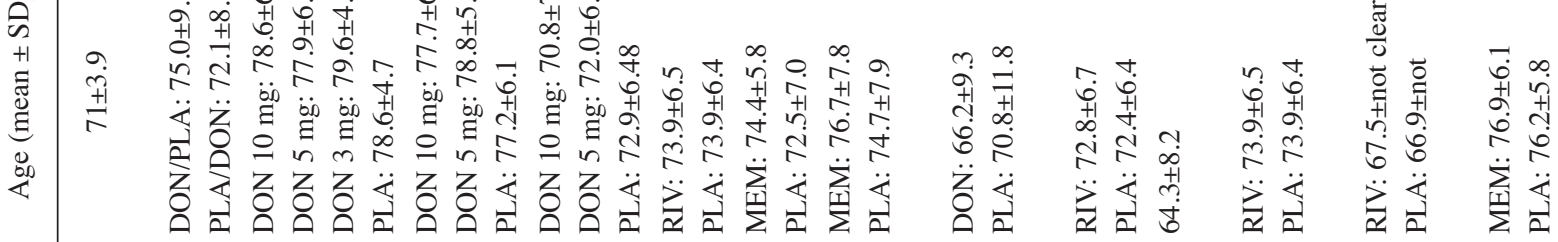

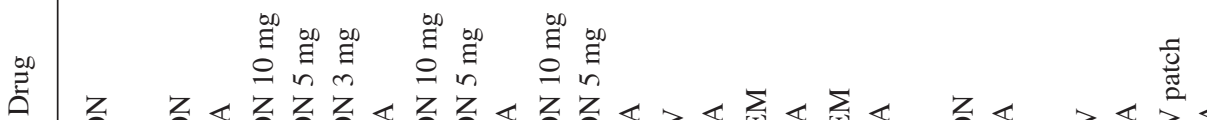

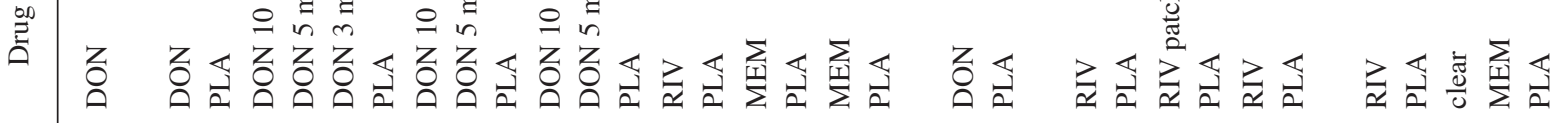

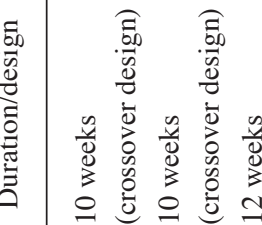

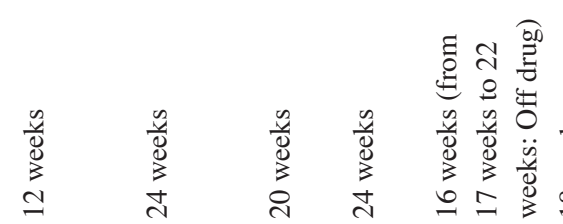

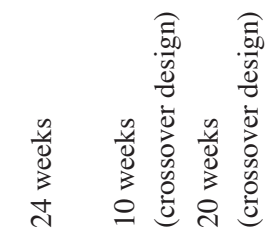

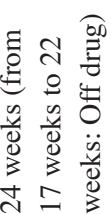

旁

a

$\stackrel{9}{0}$

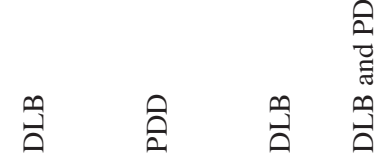

容<smiles>C1CC2CCCC2C1</smiles>

育

ิิ 
fall, somnolence, insomnia, hallucinations), urinary tract infection and respiratory tract infection; however, most adverse events were mild or moderate. As presented in Fig. 9, the results of the meta-analysis revealed more adverse events in the treatment groups compared with those in the placebo group ( $\mathrm{R}=1.09$; 95\% CI: 1.04-1.16; $\mathrm{P}=0.001)$. However, among the subgroups, only the rivastigmine group experienced significantly more adverse events compared the placebo group ( $\mathrm{RR}=1.18$; 95\% CI: 1.08-1.29; $\mathrm{P}=0.0001$; data not shown). Donepezil and memantine did not produce any significant adverse events compared with the placebo.

Publication bias. The publication bias regarding cognitive and motor function was determined by drawing Begg's funnel plots (Fig. 10A and B). The shape of the funnel plots exhibited no obvious asymmetry, which indicated the absence of significant heterogeneity between these selected studies, and the pooled results were not influenced by publication bias.

Sensitivity analysis. A sensitivity analysis was conducted to assess the stability of the results by sequential removal of individual studies. The heterogeneity $\left(\mathrm{I}^{2}=75 \%\right)$ in global cognitive function is shown in Fig. 3, the study by Li et al (10) did not provide the mean differences with SDs, but rather electing to report the mean and SDs prior to and following treatment, which may have resulted in data conversion-associated errors. Following the exclusion of the study, the analysis results did not change. In Fig. 4A, numerous trials that examined cognitive domains were then assessed $\left(\mathrm{I}^{2}=78 \%\right)$, it was found that the results did not change following the sequential removal of individual studies. The authors of the current study estimated that there was variability in measurement precision.

\section{Discussion}

The present meta-analysis assessed the efficacy and safety of cholinesterase inhibitors and memantine in the treatment of CIND-PD, PDD and DLB, which contained four new more articles than a previous meta-analysis (9). To the best of our knowledge, the present study was the first meta-analysis to report on the effect of cholinesterase inhibitors and memantine in subjects with CIND-PD, PDD and DLB, including cognitive domains (attention, processing speed, executive functions, memory, visuospatial cognition and language). The results indicated that cholinesterase inhibitors had beneficial effects on attention, processing speed, executive functions, memory and language, but did not improve visuospatial cognition when compared with the placebo. Furthermore, memantine was revealed to improve attention, processing speed and executive functions. However, cholinesterase inhibitors and memantine did not significantly reduce falling. Compared with the placebo, more adverse events occurred in the pooled cholinesterase inhibitors and memantine group than in the placebo group. However, a subgroup analysis indicated that only the rivastigmine group experienced significantly more adverse events than the placebo group, while donepezil and memantine did not produce any significant adverse events.

Consistent with the results of previous meta-analyses, the present study indicated that donepezil was beneficial for DLB 
A

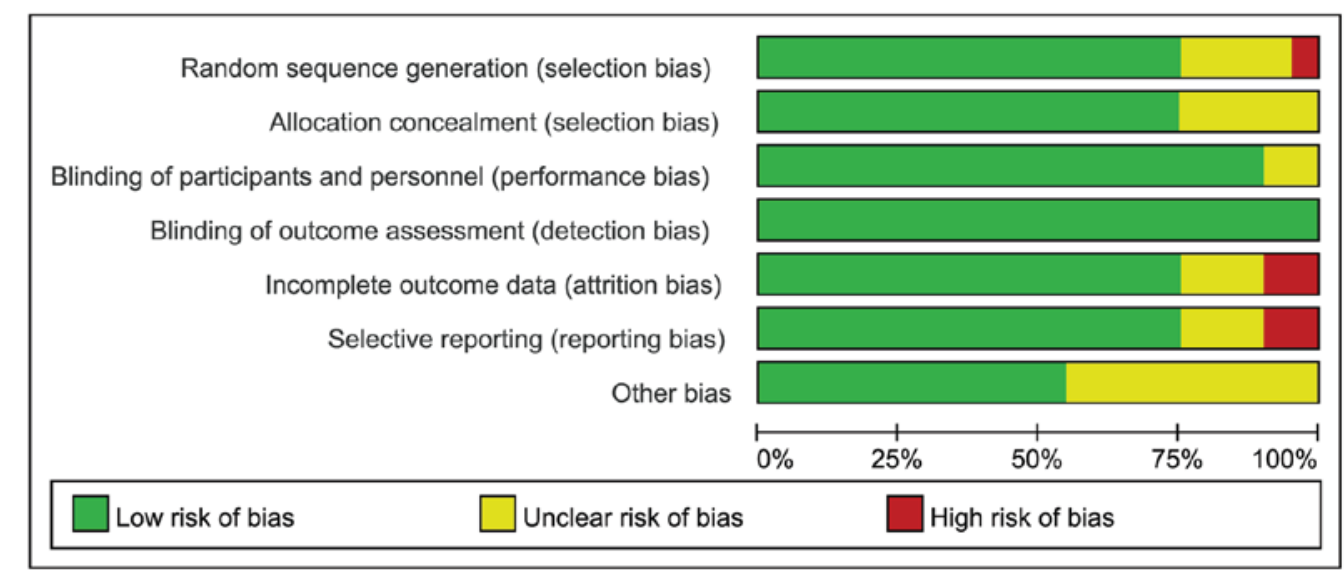

B

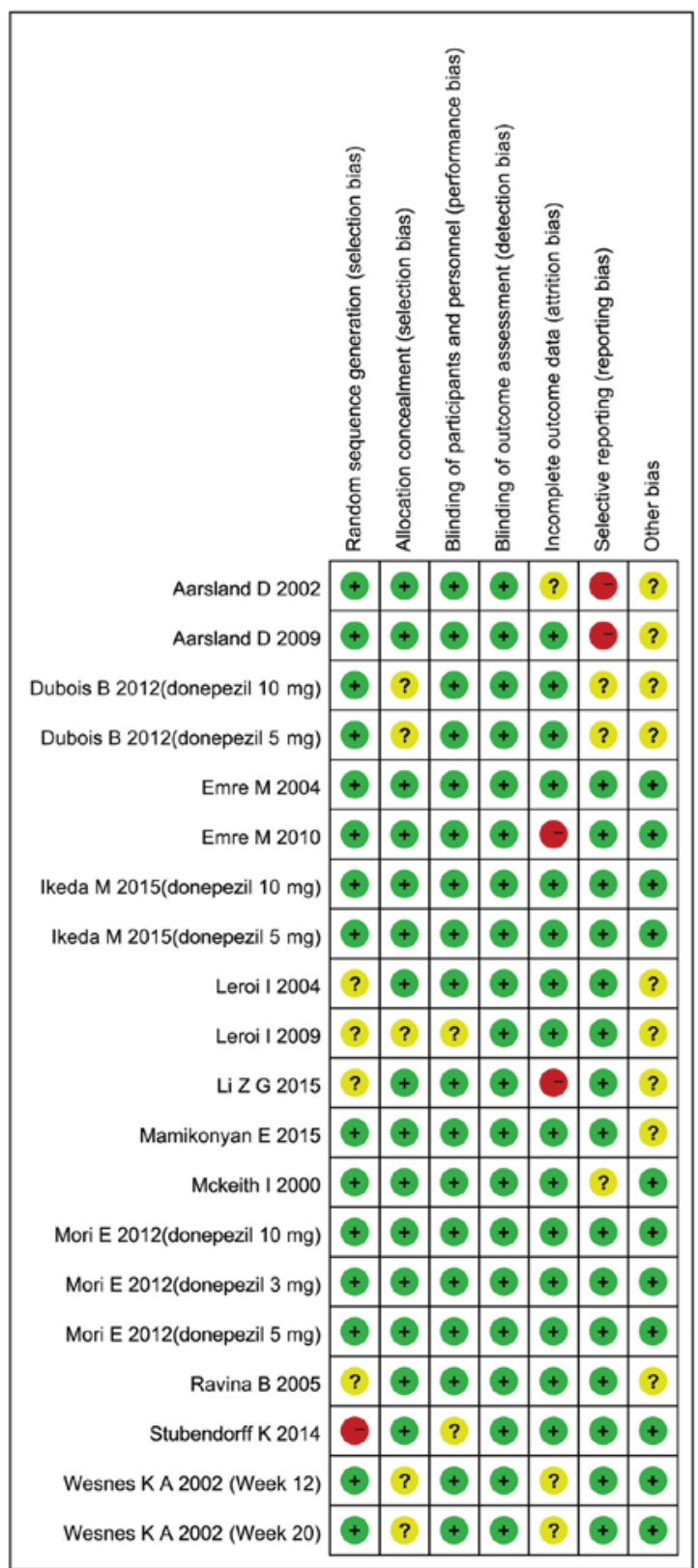

Figure 2. Risk of bias graphs. Review authors' judgments on each risk of bias item (A) presented as percentages across all included studies and (B) for each included study.

regarding cognitive function and global impression, but not in any other aspects. Recently published secondary analyses of donepezil suggest statistically significant advantages of donepezil over placebo regarding aspects of Behavioural 


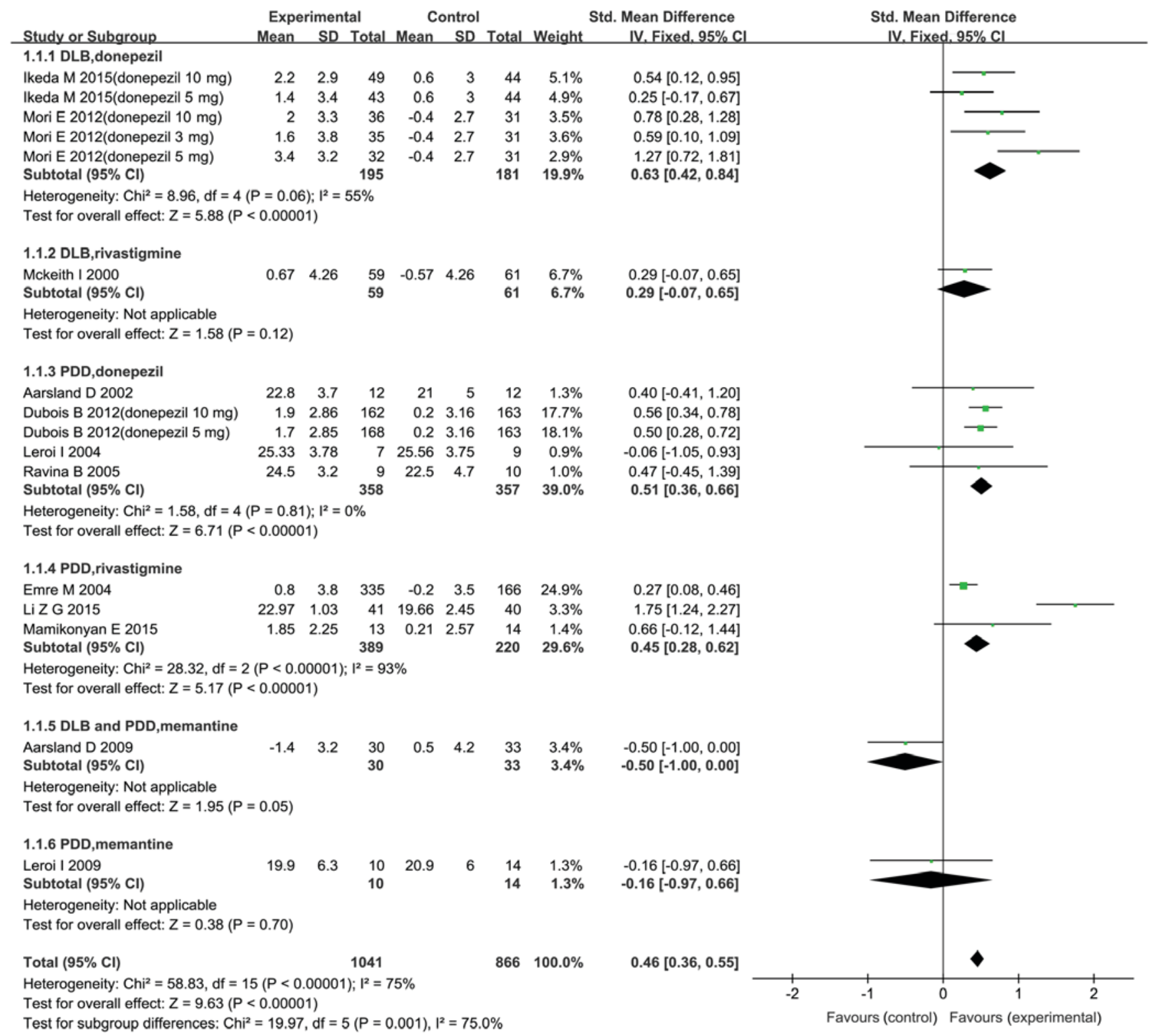

Figure 3. Forest plot of the meta-analysis of cognitive outcomes determined by Mini-Mental State Examination and Montreal Cognitive Assessment for various drugs and doses. The risk ratio is presented as green squares, with the horizontal lines indicating the confidence interval. Combined results for all studies are presented as black diamonds. CI, confidence interval; IV, inverse variance; SD, standard deviation; df, degrees of freedom; PDD, Parkinson's disease with dementia; DLB, dementia with Lewy bodies.

and Psychological Symptoms of Dementia (BPSD), improvement of cognitive function and visual hallucinations (36-38). Manabe et al (36) observed that $10 \mathrm{mg}$ donepezil improved BPSD in DLB. Mori et al (37) reported that increasing the dose of donepezil from 5 to $10 \mathrm{mg}$ enhanced the effect in improving cognitive function in DLB with little influence on the safety. Ukai et al (38) reported that donepezil was highly effective against visual hallucinations in DLB.

Galanthamine is another cholinesterase inhibitor. To date, the potential benefits of galanthamine have remained insufficiently demonstrated, except for an open-label trial. Litvinenko et al (39) reported that galanthamine improved cognitive function, behavioral symptoms, daily activity and the number of falls. Galanthamine treatment was not associated with any significant adverse events when compared with the placebo.
The results of the present meta-analysis revealed that memantine only had a minor side effect on the participants; however, this is in contrast to the meta-analysis by Matsunaga et al (6). This discrepancy may have been due to the fact that the analysis of the present study included two further trials, which may have provided more accurate results. Larsson et al (40) reported that memantine decreases the probable rapid eye movement sleep behavioral disorder in patients with DLB and PDD.

Safety is as important as the efficacy of the interventions in clinical studies. All of the three drugs assessed in the present study adhered to certain safety standards; however, rivastigmine produced more adverse events compared with those in the placebo group. Of note, donepezil and memantine did not produce any significant adverse events compared with the placebo. None of the drugs improved or 
A

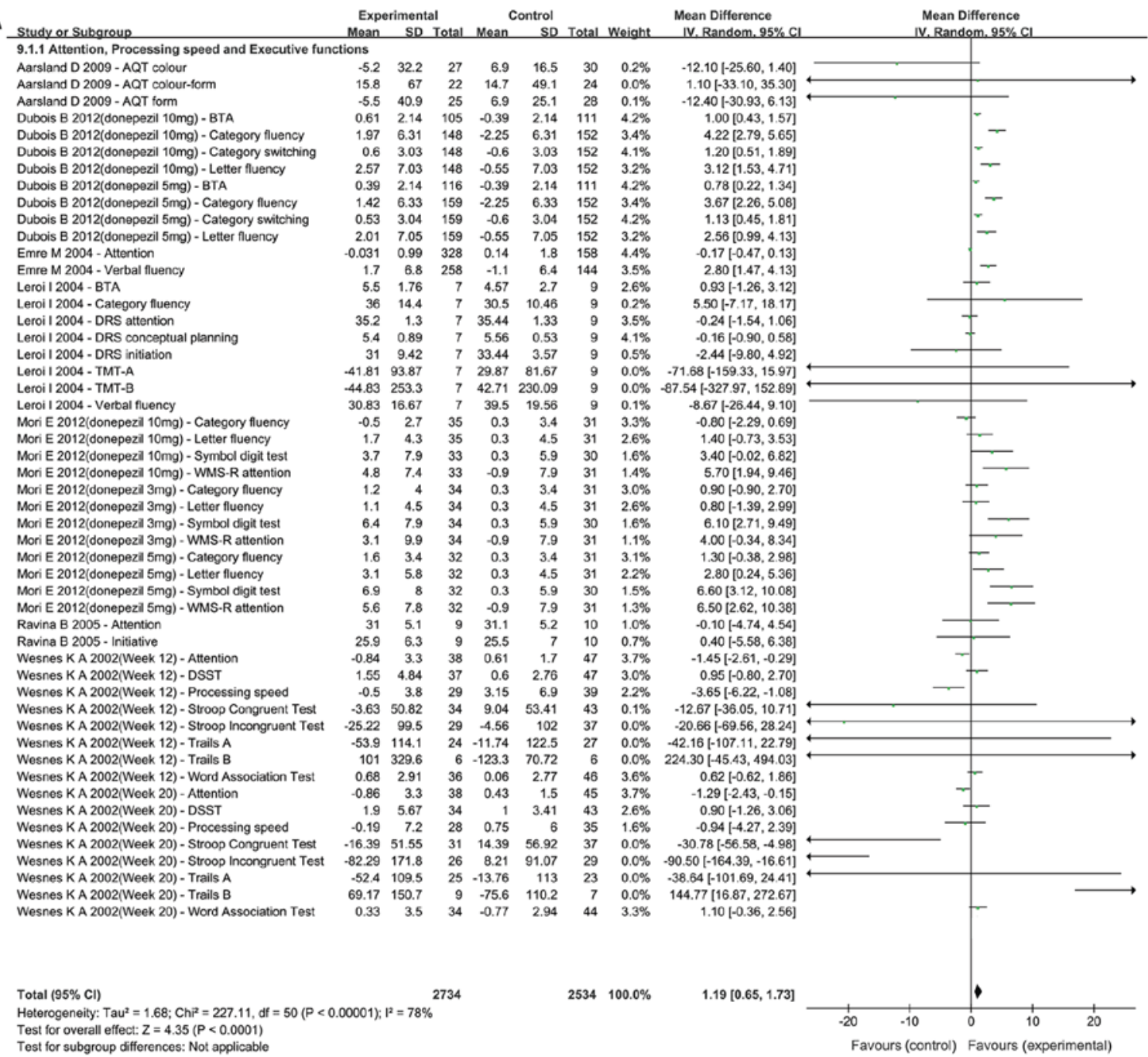

B

Study or Subgroup
9.2.1 Momory
Leroi I 2004 - DRS-memory
Leroi I 2004 - HVLT-R Recall
Leroi I 2004 - HVLT-R Recognition
Leroi I 2004 - HVLT-R Total
Mori E 2012(donepozil 10mg) -VPTA form recognition
Mori E 2012(donepezil 3mg) - VPTA form recognition
Mori E 2012(donepezil 5mg) - VPTA form recognition
Wesnes K A 2002(Week 12)-Episodic secondary memory
Wesnes K A 2002(Week 12)-Overall quality of memory
Wesnes K A 2002(Week 12)-Quality of working memory
Wesnes K A 2002(Week 20)-Episodic secondary memory
Wesnes K 2 2002(Week 20)-Overall quality of memory
Wesnes K A 2002(Week 20)-Quality of working memory

Experimental Control

Mean Difference

$\begin{array}{rrrrrrrr}22.2 & 4.66 & 7 & 19.56 & 4.28 & 9 & 0.1 \% & 2.64[-1.80,7.08] \\ 6.3 & 3.5 & 7 & 5.2 & 4.3 & 9 & 0.1 \% & 1.10[-2.72,4.92] \\ 10.2 & 2.6 & 7 & 10.8 & 1.3 & 9 & 0.4 \% & -0.60[-2.71,1.51] \\ 20.83 & 8.66 & 7 & 18.22 & 8.29 & 9 & 0.0 \% & 2.61[-5.79,11.01] \\ -1 & 2.1 & 34 & -1 & 2.9 & 31 & 1.1 \% & 0.00[-1.24,1.24] \\ 0 & 3.7 & 34 & -1 & 2.9 & 31 & 0.7 \% & 1.00[-0.61,2.61] \\ -1.1 & 2.4 & 32 & -1 & 2.9 & 31 & 1.0 \% & -0.10[-1.42,1.22] \\ 0.131 & 0.656 & 34 & -0.125 & 0.526 & 44 & 23.6 \% & 0.26[-0.01,0.33] \\ 0.424 & 1.06 & 34 & -0.159 & 0.72 & 44 & 10.0 \% & 0.58[0.17 .1 .00] \\ 0.257 & 0.672 & 30 & -0.008 & 0.484 & 40 & 21.4 \% & 0.27[-0.02,0.55] \\ -0.023 & 0.731 & 33 & -0.13 & 0.512 & 41 & 19.8 \% & 0.11[-0.19,0.40] \\ 0.0991 & 1.28 & 33 & -0.141 & 0.794 & 41 & 6.9 \% & 0.24[-0.26,0.74] \\ 0.105 & 0.804 & 30 & -0.02 & 0.56 & 38 & 15.0 \% & 0.13[-0.21,0.46]\end{array}$

IV. Fixed. $95 \% \mathrm{C}$

Wesnes K A 2002(Week 20)-Quality of working memery

Total $(95 \% \mathrm{Cl})$

Heterogeneity: $\mathrm{Chi}^{2}=7.38$, of $=12(\mathrm{P}=0.83) ; \mathrm{I}^{2}=0 \%$

$38 \quad 15.0 \%-0.13(-0.21,0.46]$

Test for overall effect: $Z=3.58(P=0.0003)$

$377 \quad 100.0 \% \quad 0.24[0.11,0.37]$

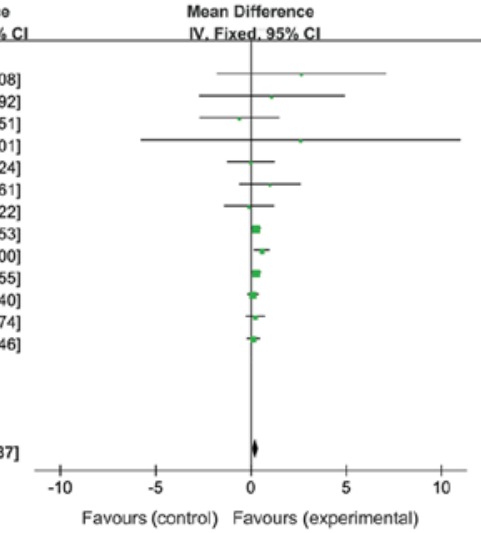

\section{C} $\begin{array}{ccccc} & \text { Experimental } & \text { Control } & \text { Mean Difference } & \text { Mean Difference } \\ \text { Study or Subgroup } & \text { Mean SD Total Mean SD Total Weight } & \text { IV. Fixed. } 95 \% \mathrm{Cl} & \text { IV. Fixed, 95\% C }\end{array}$ 9.3.1 Visuospatial Emre M 2004 - Ten Point Clock-Drawing score Leroi I 2004 - Beery VMI Leroi I 2004 - DRS Construction Wesnes K A 2002(Week 12) - Block Design Test \begin{tabular}{lllllllll} 
Wesnes K A 2002(Week 12) - Block Design Test & 1.3 & 4.9 & 30 & 2.1 & 4.9 & 42 & $6.4 \%$ & $-0.80[-3.10,1.50]$ \\
Wesnes K A 2002(Week 20) - Block Design Test & 1.7 & 7.6 & 31 & 1.7 & 4.8 & 39 & $3.6 \%$ & 0.00 \\
\hline
\end{tabular}

$\begin{array}{llllllll}0.5 & 2.5 & 49 & -0.6 & 2.4 & 30 & 27.5 \% & 1.10[-0.01,2.21]\end{array}$ $\begin{array}{llllllll}14.8 & 5.54 & 7 & 14.44 & 4.82 & 9 & 1.3 \% & 0.36[-4.81,5.53]\end{array}$ $\begin{array}{lllllllll}5.4 & 0.9 & 7 & 5.6 & 0.5 & 9 & 61.2 \% & -0.20 & {[-0.94,0.54]}\end{array}$ $\begin{array}{rrrrrrrr}1.3 & 4.9 & 30 & 2.1 & 4.9 & 42 & 6.4 \% & -0.80[-3.10,1.50]\end{array}$

Total $(95 \% \mathrm{Cl})$

Heterogeneity: $\mathrm{Chi}^{2}=4.35, \mathrm{df}=4(P=0.36) ; 1^{2}=8 \%$ Test for overall effect: $Z=0.45(P=0.65)$ Test for subgroup differences: Not applicable
124

$129 \quad 100.0 \% \quad 0.13[-0.45,0.71]$

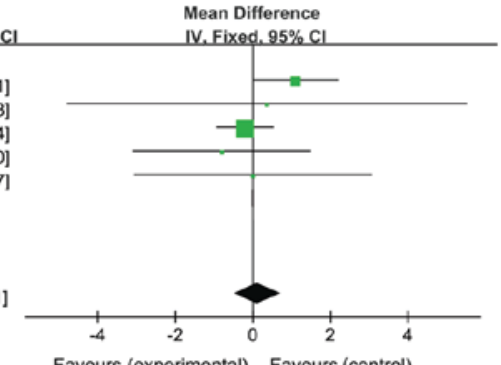

Favours (experimental) Favours (control)

Figure 4. Forest plot of the meta-analysis for the cognitive domains of (A) attention, processing speed and executive functions, (B) memory for donepezil, rivastigmine and memantine, and $(\mathrm{C})$ visuospatial cognition. The risk ratio is presented as green squares, with the horizontal lines indicating the confidence interval. Combined results for all studies are presented as black diamonds. 


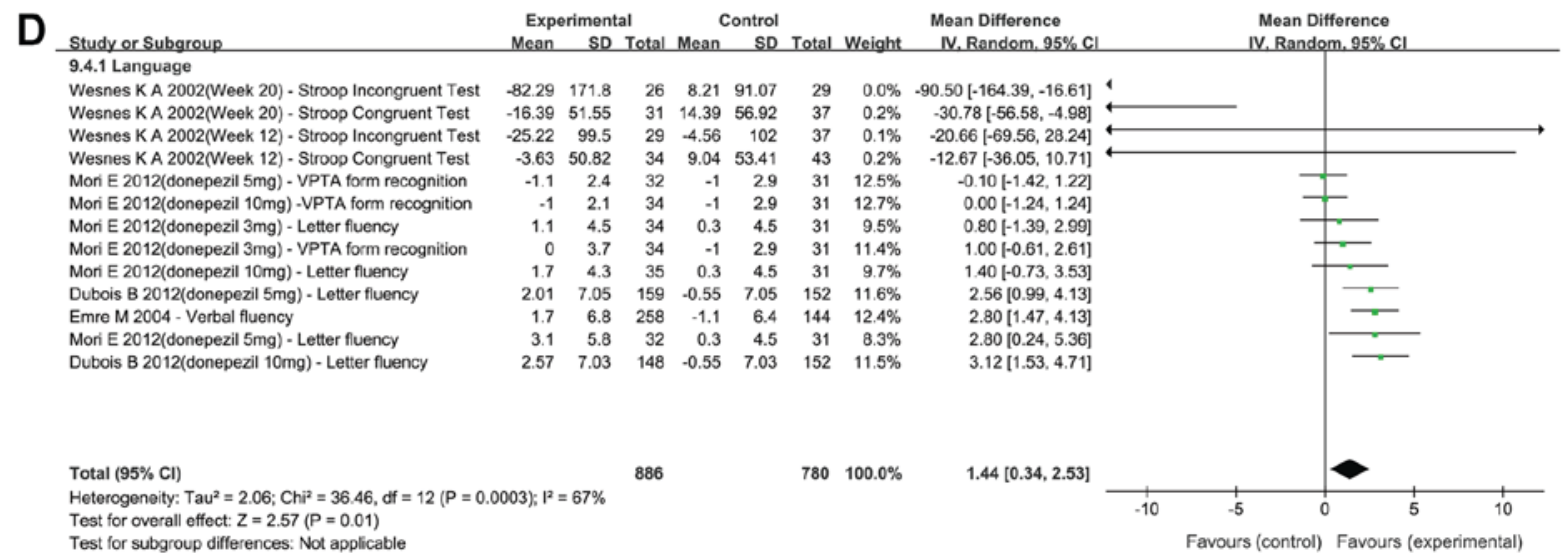

Figure 4. Continued. Forest plot of the meta-analysis for the cognitive domain of (D) language for donepezil and rivastigmine. The risk ratio is presented as green squares, with the horizontal lines indicating the confidence interval. Combined results for all studies are presented as black diamonds. CI, confidence interval; IV, inverse variance; SD, standard deviation; df, degrees of freedom; VPTA, Visual Perception Test for Agnosia; AQT, A Quick Test of Cognitive Speed; WMS-R, Wechsler Memory Scale-Revised; BTA, Brief Test of Attention; DRS, Dementia Rating Scale; TMT, Trial Making Test; DSST, Digit Symbol Substitution Test; HVLT-R, Hopkins Verbal Learning Test-Revised.

\begin{tabular}{|c|c|c|c|c|c|c|c|c|c|c|}
\hline Study or Subgroup & \multicolumn{2}{|c|}{ Experimental } & \multicolumn{2}{|c|}{ Control } & Weight & $\begin{array}{l}\text { Risk Ratio } \\
\text { M-H.Fixed. } 95 \% \mathrm{Cl}\end{array}$ & \multicolumn{4}{|c|}{$\begin{array}{l}\text { Risk Ratio } \\
\text { M-H. Fixed. } 95 \% \mathrm{CI}\end{array}$} \\
\hline \multicolumn{11}{|l|}{ 2.1.1 DLB, donepezil } \\
\hline Mori E 2012(donepezil $10 \mathrm{mg}$ ) & 18 & 28 & 10 & 30 & $3.2 \%$ & $1.93[1.08,3.43]$ & & & & \\
\hline Mori E 2012(donepezil $3 \mathrm{mg}$ ) & 22 & 32 & 10 & 30 & $3.4 \%$ & $2.06[1.18,3.60]$ & & & & \\
\hline Mori E 2012(donepezil $5 \mathrm{mg}$ ) & 22 & 31 & 10 & 30 & $3.3 \%$ & $2.13[1.22,3.70]$ & & & & \\
\hline Subtotal $(95 \% \mathrm{Cl})$ & & 91 & & 90 & $9.9 \%$ & $2.04[1.48,2.83]$ & & & & \\
\hline Total events & 62 & & 30 & & & & & & & \\
\hline \multicolumn{11}{|c|}{ Heterogeneity: $\mathrm{Chi}^{2}=0.06, d f=2(P=0.97) ; 1^{2}=0 \%$} \\
\hline \multicolumn{11}{|c|}{ Test for overall effect: $Z=4.31(P<0.0001)$} \\
\hline \multicolumn{11}{|l|}{ 2.1.2 PDD,donepezil } \\
\hline Dubois B 2012(donepezil $5 \mathrm{mg}$ ) & 70 & 177 & 68 & 170 & $22.7 \%$ & $0.99[0.76,1.28]$ & & & & \\
\hline Dubois B 2012(donepezil $10 \mathrm{mg}$ ) & 85 & 170 & 68 & 170 & $22.3 \%$ & $1.25[0.99,1.59]$ & & & & \\
\hline Aarsland D 2002 & 5 & 12 & 2 & 12 & $0.7 \%$ & $2.50[0.60,10.46]$ & & & & \\
\hline Subtotal $(95 \% \mathrm{Cl})$ & & 359 & & 352 & $45.6 \%$ & $1.14[0.96,1.35]$ & & & & \\
\hline Total events & 160 & & 138 & & & & & & & \\
\hline \multicolumn{11}{|c|}{ Heterogeneity: $\mathrm{Chi}^{2}=2.89, \mathrm{df}=2(\mathrm{P}=0.24) ; \mathrm{I}^{2}=31 \%$} \\
\hline \multicolumn{11}{|c|}{ Test for overall effect: $Z=1.46(P=0.14)$} \\
\hline \multicolumn{11}{|l|}{ 2.1.3 PDD, rivastigmine } \\
\hline Emre M 2004 & 134 & 329 & 49 & 165 & $21.4 \%$ & $1.37[1.05,1.79]$ & & & & \\
\hline Subtotal $(95 \% \mathrm{Cl})$ & & 329 & & 165 & $21.4 \%$ & $1.37[1.05,1.79]$ & & & & \\
\hline Total events & 134 & & 49 & & & & & & & \\
\hline \multicolumn{11}{|l|}{ Heterogeneity: Not applicable } \\
\hline \multicolumn{11}{|c|}{ Test for overall effect: $Z=2.31(P=0.02)$} \\
\hline \multicolumn{11}{|l|}{ 2.1.4 DLB,memantine } \\
\hline Emre M 2010 & 16 & 33 & 16 & 41 & $4.7 \%$ & $1.24[0.74,2.09]$ & & & & \\
\hline Subtotal $(95 \% \mathrm{Cl})$ & & 33 & & 41 & $4.7 \%$ & $1.24[0.74,2.09]$ & & & & \\
\hline Total events & 16 & & 16 & & & & & & & \\
\hline \multicolumn{11}{|l|}{ Heterogeneity: Not applicable } \\
\hline \multicolumn{11}{|c|}{ Test for overall effect: $Z=0.82(P=0.41)$} \\
\hline \multicolumn{11}{|l|}{ 2.1.5 PDD, memantine } \\
\hline Emre M 2010 & 31 & 60 & 28 & 56 & $9.5 \%$ & $1.03[0.72,1.48]$ & & & & \\
\hline Leroi I 2009 & 6 & 10 & 6 & 14 & $1.6 \%$ & $1.40[0.64,3.08]$ & & & & \\
\hline Subtotal $(95 \% \mathrm{Cl})$ & & 70 & & 70 & $11.1 \%$ & $1.09[0.78,1.51]$ & & & & \\
\hline Total events & 37 & & 34 & & & & & & & \\
\hline \multicolumn{11}{|c|}{ Heterogeneity: $\mathrm{Chi}^{2}=0.47, \mathrm{df}=1(\mathrm{P}=0.49) ; \mathrm{I}^{2}=0 \%$} \\
\hline Test for overall effect: $Z=0.50(P$ & $=0.61)$ & & & & & & & & & \\
\hline 2.1.6 DLB and PDD,memantine & & & & & & & & & & \\
\hline Stubendorff K 2014 & 12 & 18 & 9 & 14 & $3.3 \%$ & $1.04[0.62,1.73]$ & & & & \\
\hline Aarsland D 2009 & 19 & 30 & 13 & 33 & $4.1 \%$ & $1.61[0.97,2.66]$ & & & & \\
\hline Subtotal $(95 \% \mathrm{Cl})$ & & 48 & & 47 & $7.4 \%$ & $1.35[0.94,1.94]$ & & & & \\
\hline Total events & 31 & & 22 & & & & & & & \\
\hline Heterogeneity: $\mathrm{Chi}^{2}=1.50, \mathrm{df}=1$ & $P=0.22)$ & ${ }^{2}=33 \%$ & & & & & & & & \\
\hline Test for overall effect: $Z=1.63(P$ & $=0.10)$ & & & & & & & & & \\
\hline Total $(95 \% \mathrm{Cl})$ & & 930 & & 765 & $100.0 \%$ & $1.29[1.15,1.45]$ & & & 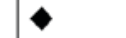 & \\
\hline Total events & 440 & & 289 & & & & & & & \\
\hline Heterogeneity: $\mathrm{Chi}^{2}=15.86, \mathrm{df}=$ & $1(P=0.15$ & $; 1^{2}=31$ & & & & & 0.1 & 0.5 & 1 & $5 \quad 10$ \\
\hline $\begin{array}{l}\text { Test for overall effect: } Z=4.39 \text { (P } \\
\text { Test for subgroup differences: Chi }\end{array}$ & $\begin{array}{l}=0.0001) \\
=11.03 \mathrm{o}\end{array}$ & $f=5(P$ & $=0.05) \mathrm{I}^{\mathrm{2}} \mathrm{k}$ & $=54.7 \mathrm{r} \cdot \mathrm{r} \cdot \mathrm{l}$ & & & $\begin{array}{l}0.2 \\
\text { Fav }\end{array}$ & $\begin{array}{l}0.5 \\
\mathrm{rs}(\mathrm{con}\end{array}$ & 1 ${ }^{2}$ & $\begin{array}{cc}5 & 10 \\
\text { eerimental) }\end{array}$ \\
\hline
\end{tabular}

Figure 5. Forest plot of the meta-analysis of Clinical Global Impression of Change by drug and dose. The risk ratio is presented as green squares, with the horizontal lines indicating the confidence interval. Combined results for all studies are presented as black diamonds. CI, confidence interval; M-H, Mantel-Haentzel; df, degrees of freedom; PDD, Parkinson's disease with dementia; DLB, dementia with Lewy bodies. 


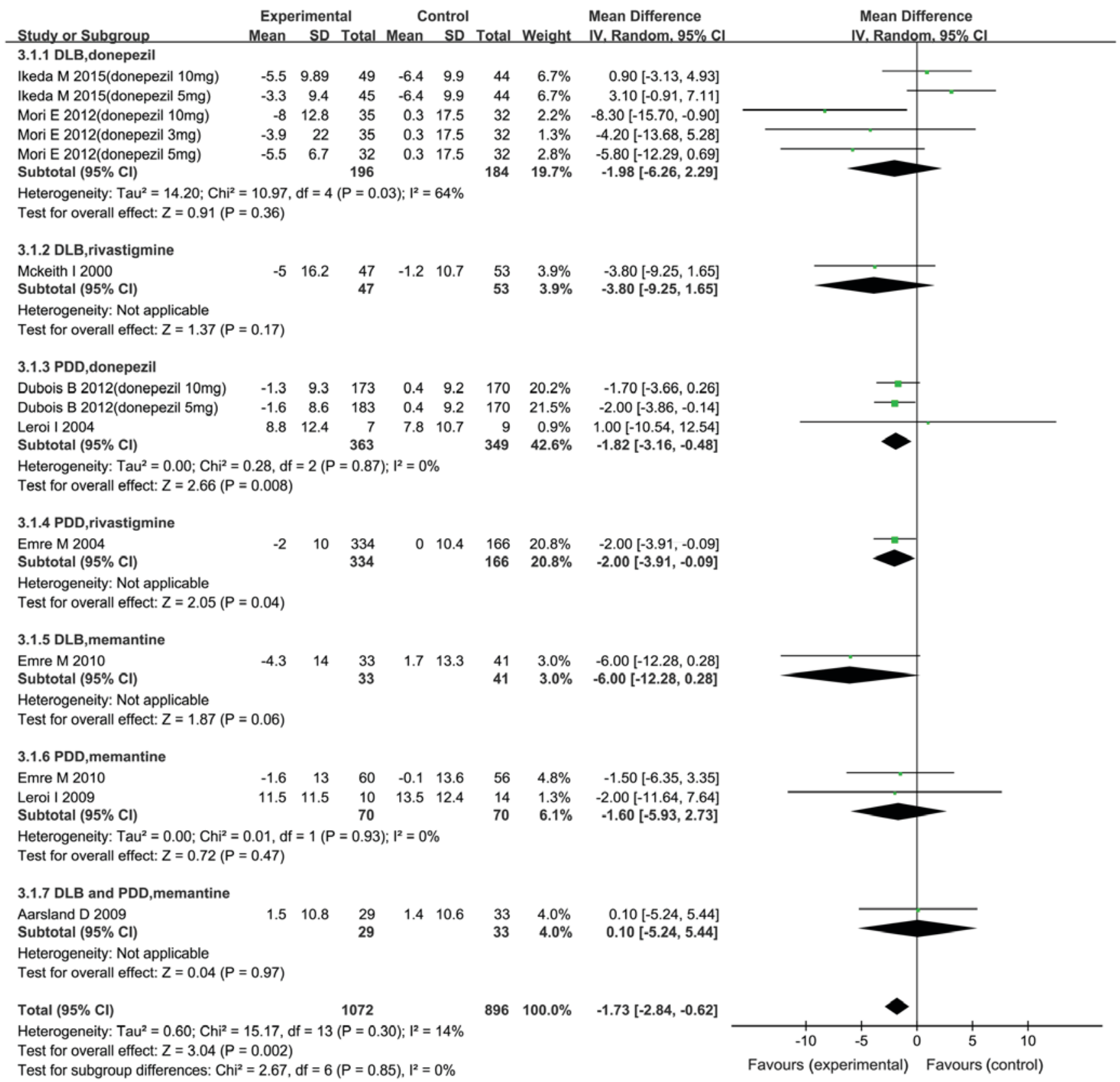

Figure 6. Forest plot of the meta-analysis of behavioral symptoms according to the 10-Item Neuropsychiatric Inventory by drug and dose. The risk ratio is presented as green squares, with the horizontal lines indicating the confidence interval. Combined results for all studies are presented as black diamonds. CI, confidence interval; IV, inverse variance; SD, standard deviation; df, degrees of freedom; PDD, Parkinson's disease with dementia; DLB, dementia with Lewy bodies.

aggravated the symptoms of Parkinsonism compared with the placebo. Emre et al (41) reported that in a 76-week, prospective, open-label, randomized study in PDD patients aged 50 to 85 years, rivastigmine exhibited long-term safety.

Of note, the present meta-analysis had several limitations. First, even though 15 trials were included, the number of participants was small, and the results may not sufficiently allow for making any final conclusions. Furthermore, a complete evaluation of all interventions applied was impossible due to a lack of data. In addition, most of the trials included were relatively short, and more long-term trials with relatively longer follow-up periods similar to that by Li et al (10) lasting 12 months, are required for further evaluation. In addition, in the cognitive domains analysis with $\mathrm{I}^{2}=78 \%$, variation in at times overlapping interventions, heterogeneity in outcomes assessed and low number of controls were of greatest concern. The studies examined were performed across multiple countries with instruments that may appear to be similar, prima facie, but may substantially differ in how they sequentially remove individual studies (42). The authors of the current study combined different doses of the same drug for analysis, thus this may lead to biased results; this must be taken into consideration and eliminated in future studies.

In conclusion, cholinesterase inhibitors provide a benefit not only regarding global cognitive function, CGIC and behavioral symptoms, but also in cognitive domains. 


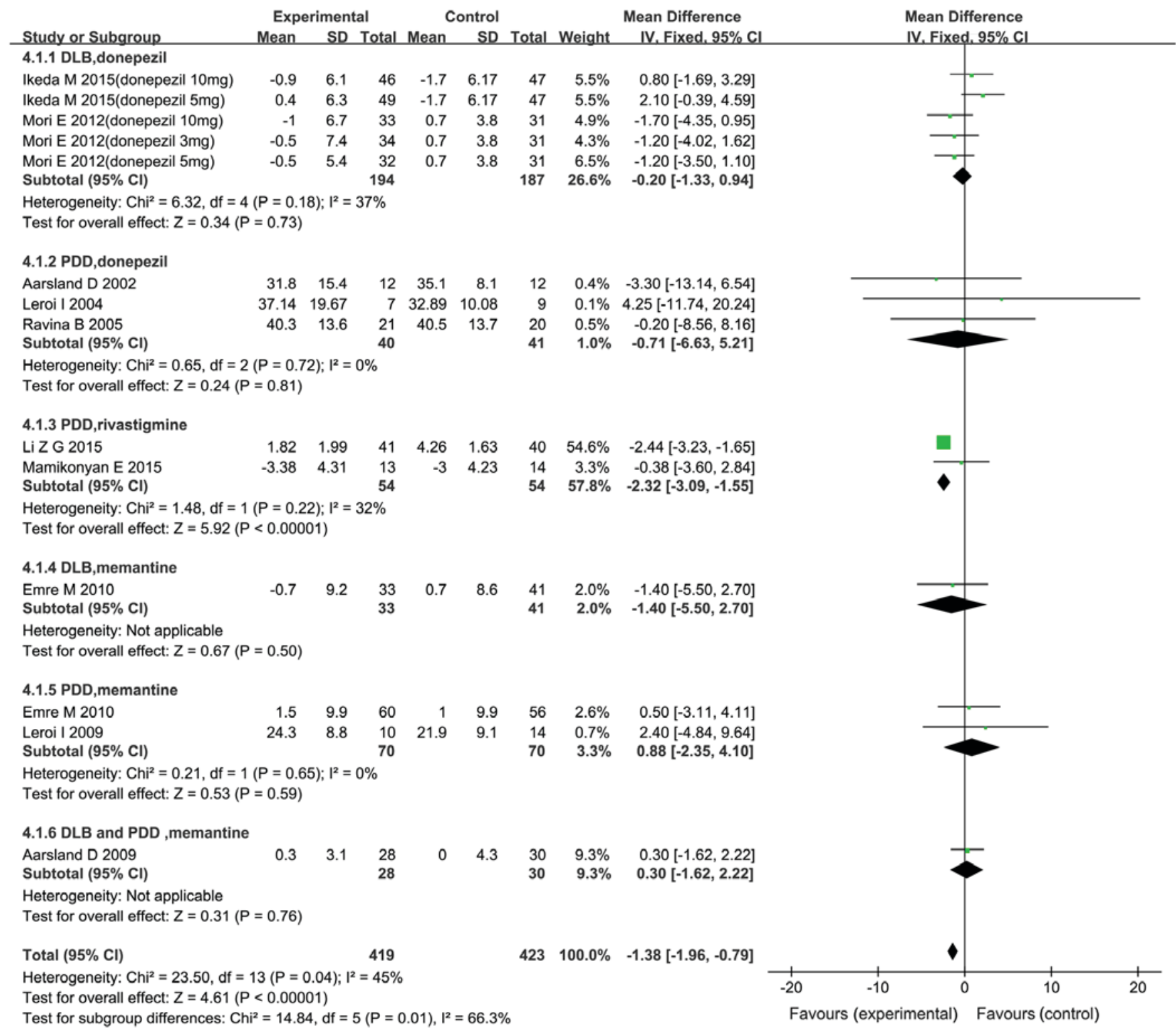

Figure 7. Forest plot of the meta-analysis of motor function on the Unified Parkinson's Disease Rating Scale-motor by drug and dose. The risk ratio is presented as green squares, with the horizontal lines indicating the confidence interval. Combined results for all studies are presented as black diamonds. CI, confidence interval; IV, inverse variance; SD, standard deviation; df, degrees of freedom; PDD, Parkinson's disease with dementia; DLB, dementia with Lewy bodies.

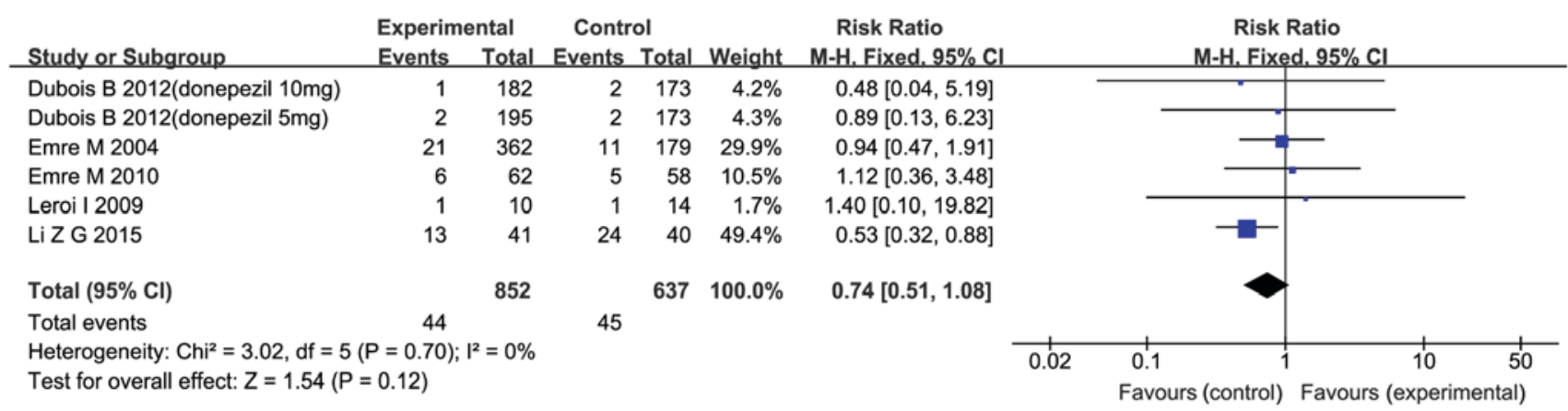

Figure 8. Forest plot of the meta-analysis of falling by drug and dose for Parkinson's disease with dementia and cognitive impairment in Parkinson's disease. The risk ratio is presented as blue squares, with the horizontal lines indicating the confidence interval. Combined results for all studies are presented as black diamonds. CI, confidence interval; M-H, Mantel-Haentzel; df, degrees of freedom.

Memantine treatment results in a significant improvement in attention, processing speed and executive functions according to sensitivity analysis. However, cholinesterase inhibitors and memantine do not significantly reduce falling. Finally, 


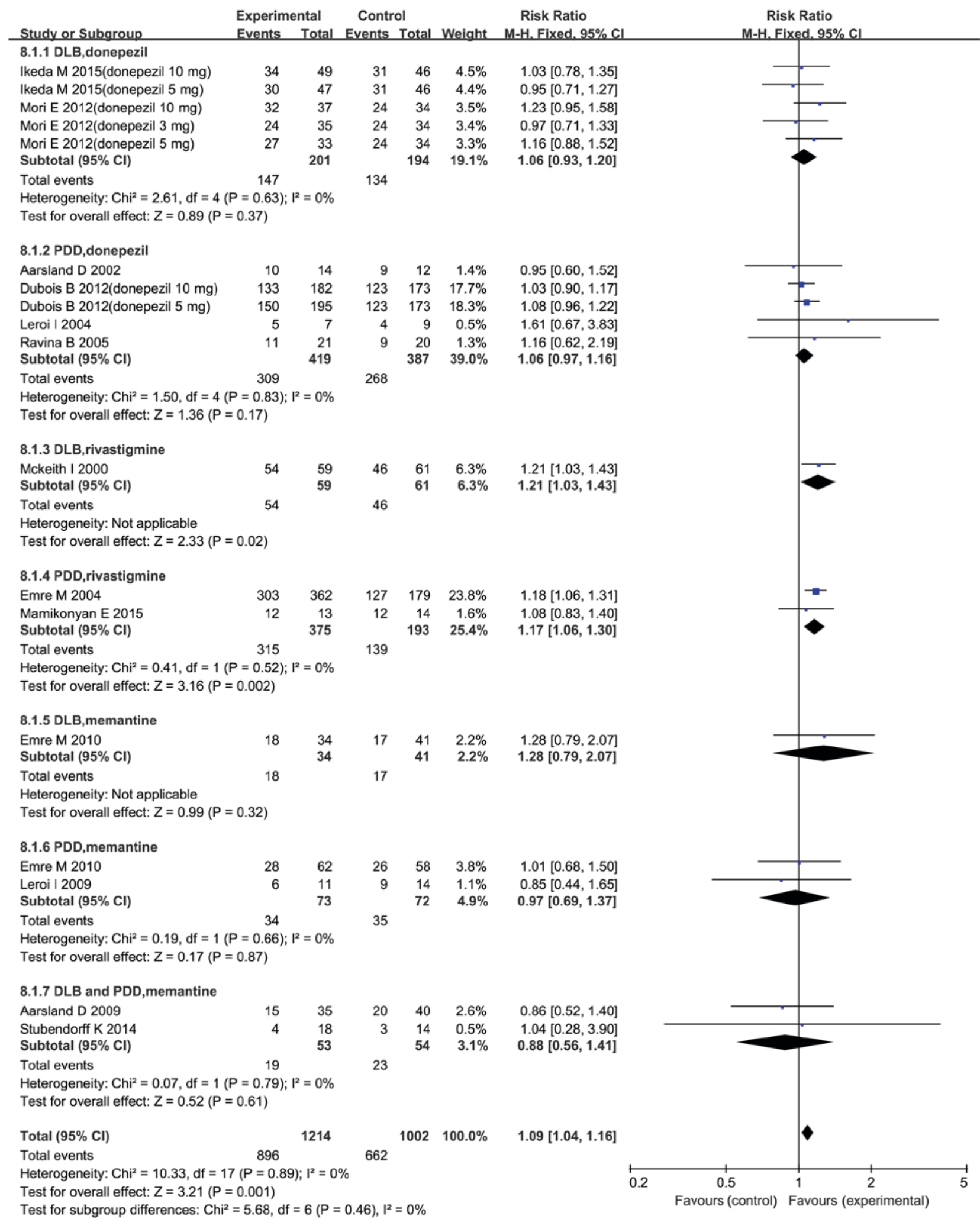

Figure 9. Forest plot of the meta-analysis of adverse events by drug and dose. The risk ratio is presented as blue squares, with the horizontal lines indicating the confidence interval. Combined results for all studies are presented as black diamonds. CI, confidence interval; M-H, Mantel-Haentzel; df, degrees of freedom; PDD, Parkinson's disease with dementia; DLB, dementia with Lewy bodies.

cholinesterase inhibitors and memantine are associated with good safety outcomes, with only the rivastigmine group exhibiting significant adverse events compared with the placebo group. However, considering the limitations of the present study, the results may not sufficiently support the use of cholinesterase inhibitors and memantine as treatments for CIND-PD, PDD and DLB. Further clinical trials on a larger scale are imperative to better assess the efficacy and safety of cholinesterase inhibitors and memantine in CIND-PD, PDD and DLB. 

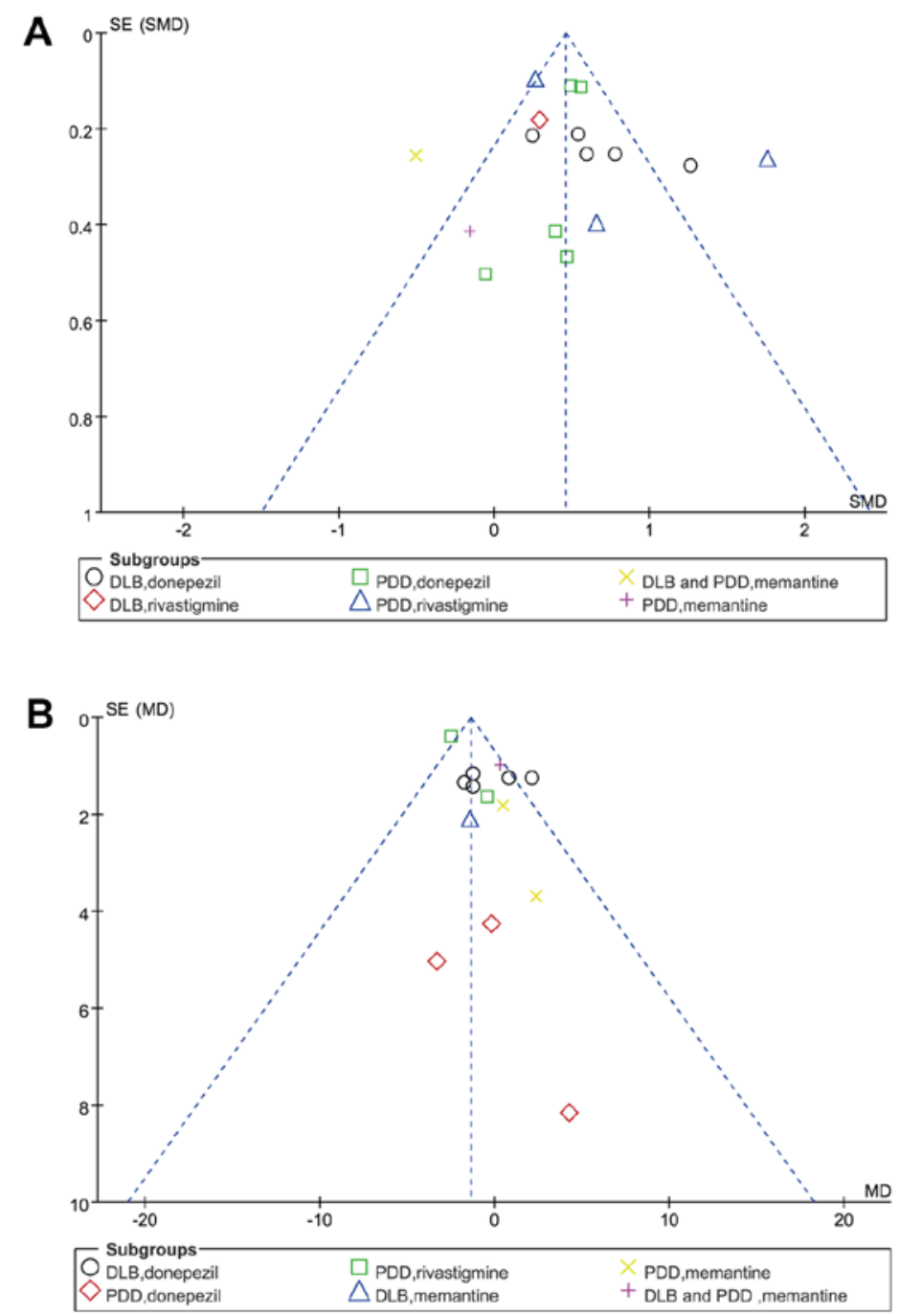

Figure 10. Funnel plot of (A) cognition and (B) motor function. PDD, Parkinson's disease with dementia; DLB, dementia with Lewy bodies; SE, standard error; SMD, standard mean difference; MD, mean difference.

\section{Acknowledgements}

Not applicable.

\section{Funding}

This study was supported by grants from the Hebei Provincial Science and Technology Support Program (grant no. 12276104D-18 to JHW) and the Major Medicine and Science Research Project (grant no. zd 2013001 to JHW).

\section{Availability of data and materials}

All data generated or analysed during this study are included in this published article.

\section{Authors' contributions}

YHM and JHW designed the analysis. YHM and JHW collected and abstracted the data, and performed the statistical analysis. YHM drafted the manuscript. YHM, JHW, PPW and YXS analysed and interpreted the data, and critically revised the manuscript for important intellectual content. All authors reviewed and approved the final report.

\section{Ethics approval and consent to participate}

Not applicable.

\section{Patient consent for publication}

Not applicable.

\section{Competing interests}

The authors declare that they have no competing interests.

\section{References}

1. Aarsland D, Andersen K, Larsen JP, Lolk A, Nielsen H and Kragh-Sørensen P: Risk of dementia in Parkinson's disease-A community-based, prospective study. Neurology 56: 730-736, 2001.

2. Aarsland D, Zaccai J and Brayne C: A systematic review of prevalence studies of dementia in Parkinson's disease. Mov Disord 20: 1255-1263, 2005. 
3. Mueller C, Ballard C, Corbett A and Aarsland D: The prognosis of dementia with Lewy bodies. Lancet Neurol 16: 390-398, 2017.

4. Lippa CF, Duda JE, Grossman M, Hurtig HI, Aarsland D, Boeve BF, Brooks DJ, Dickson DW, Dubois B, Emre M, et al: DLB and PDD boundary issues: diagnosis, treatment, molecular pathology, and biomarkers. Neurology 68: 812-819, 2007.

5. Gomperts SN: Lewy body dementias: Dementia with Lewy bodies and Parkinson disease dementia. Continuum (Minneapolis Minn) 22: 435-463, 2016

6. Matsunaga S, Kishi T and Iwata N: Memantine for Lewy body disorders: Systematic review and meta-analysis. Am J Geriatr Psychiatry 23: 373-383, 2015.

7. Matsunaga S, Kishi T, Yasue I and Iwata N: Cholinesterase inhibitors for Lewy body disorders: A meta-analysis. Int J Neuropsychopharmacol 19: pyv086, 2015.

8. Stinton C, McKeith I, Taylor JP, Lafortune L, Mioshi E, Mak E, Cambridge V, Mason J, Thomas A and O'Brien JT: Pharmacological management of Lewy body dementia: A systematic review and meta-analysis. Am J Psychiatry 172: 731-742, 2015.

9. Wang HF, Yu JT, Tang SW, Jiang T, Tan CC, Meng XF, Wang C, Tan MS and Tan L: Efficacy and safety of cholinesterase inhibitors and memantine in cognitive impairment in Parkinson's disease, Parkinson's disease dementia, and dementia with Lewy bodies: Systematic review with meta-analysis and trial sequential analysis. J Neurol Neurosurg Psychiatry 86: 135-143, 2015.

10. Li Z, Yu Z, Zhang J, Wang J, Sun C, Wang P and Zhang J: Impact of rivastigmine on cognitive dysfunction and falling in Parkinson's disease patients. Eur Neurol 74: 86-91, 2015.

11. Gibb WR and Lees AJ: The relevance of the lewy body to the pathogenesis of idiopathic Parkinson's disease. J Neurol Neurosurg Psychiatry 51: 745-752, 1988.

12. Hughes AJ, Daniel SE, Kilford L and Lees AJ: Accuracy of clinical diagnosis of idiopathic Parkinson's disease: A clinico-pathological study of 100 cases. J Neurol Neurosurg Psychiatry 55: 181-184, 1992

13. Larsen JP, Dupont E and Tandberg E: Clinical diagnosis of Parkinson's disease. Proposal of diagnostic subgroups classified at different levels of confidence. Acta Neurol Scand 89: 242-251, 1994.

14. Litvan I, Bhatia KP, Burn DJ, Goetz CG, Lang AE, McKeith I, Quinn N, Sethi KD, Shults C, Wenning GK and Movement Disorders Society Scientific Issues Committee: Movement disorders society scientific issues committee report: SIC task force appraisal of clinical diagnostic criteria for Parkinsonian disorders. Mov Disord 18: 467-486, 2003

15. American Psychiatric Association (APA): Diagnostic and statistical manual of mental disorders. 4th edition. American Psychiatric Association, Washington, DC, 1994.

16. McKeith IG, Dickson DW, Lowe J, Emre M, O'Brien JT, Feldman H, Cummings J, Duda JE, Lippa C, Perry EK, et al: Diagnosis and management of dementia with lewy bodies: Third report of the DLB consortium. Neurology 65: 1863-1872, 2005.

17. Higgins JPT, Deeks JJ and Altman DG: Chapter 16: Special topics in statistics. In: Higgins JPT, Green S (editors), Cochrane Handbook for Systematic Reviews of Interventions Version 5.1.0 (updated March 2011). The Cochrane Collaboration, 2011. http://www.cochrane-handbook.org.

18. Higgins JPT, Altman DJ and Sterne JAC: Chapter 8: Assessing risk of bias in included studies. In: Higgins JPT, Green S (editors), Cochrane Handbook for Systematic Reviews of Interventions Version 5.1.0 (updated March 2011). The Cochrane Collaboration, 2011. http://www.cochrane-handbook.org.

19. Guyatt GH, Oxman AD, Vist GE, Kunz R, Falck-Ytter Y, Alonso-Coello P, Schünemann HJ and GRADE Working Group: GRADE: An emerging consensus on rating quality of evidence and strength of recommendations. BMJ 336: 924-926, 2008.

20. Mantel N and Haenszel W: Statistical aspects of the analysis of data from retrospective studies of disease. J Natl Cancer Inst 22 719-748, 1959

21. Higgins JP, Thompson SG, Deeks JJ and Altman DG: Measuring inconsistency in meta-analyses. BMJ 327: 557-560, 2003.

22. Ikeda M,Mori E, Matsuo K, Nakagawa M and Kosaka K: Donepezil for dementia with Lewy bodies: A randomized, placebo-controlled, confirmatory phase III trial. Alzheimers Res Ther 7: 4, 2015.

23. Mori E, Ikeda M and Kosaka K: Donepezil-DLB Study Investigators: Donepezil for dementia with Lewy bodies: A randomized, placebo-controlled trial. Ann Neurol 72: 41-52, 2012

24. Aarsland D, Laake K, Larsen JP and Janvin C: Donepezil for cognitive impairment in Parkinson's disease: A randomised controlled study. J Neurol Neurosurg Psychiatry 72: 708-712, 2002.
25. Dubois B, Tolosa E, Katzenschlager R, Emre M, Lees AJ, Schumann G, Pourcher E, Gray J, Thomas G, Swartz J, et al: Donepezil in Parkinson's disease dementia: A randomized, double-blind efficacy and safety study. Mov Disord 27: 1230-1238, 2012

26. Leroi I, Brandt J, Reich SG, Lyketsos CG, Grill S, Thompson R and Marsh L: Randomized placebo-controlled trial of donepezil in cognitive impairment in Parkinson's disease. Int J Geriatr Psychiatry 19: 1-8, 2004.

27. Ravina B, Putt M, Siderowf A, Farrar JT, Gillespie M, Crawley A, Fernandez HH, Trieschmann MM, Reichwein S and Simuni T: Donepezil for dementia in Parkinson's disease: A randomised, double blind, placebo controlled, crossover study. J Neurol Neurosurg Psychiatry 76: 934-939, 2005.

28. McKeith I, Del Ser T, Spano P, Emre M, Wesnes K, Anand R, Cicin-Sain A, Ferrara R and Spiegel R: Efficacy of rivastigmine in dementia with Lewy bodies: A randomised, double-blind, placebo-controlled international study. Lancet 356: 2031-2036, 2000.

29. Emre M, Aarsland D, Albanese A, Byrne EJ, Deuschl G, De Deyn PP, Durif F, Kulisevsky J, van Laar T, Lees A, et al: Rivastigmine for dementia associated with Parkinson's disease. N Engl J Med 351: 2509-2518, 2004.

30. Mamikonyan E, Xie SX, Melvin E and Weintraub D Rivastigmine for mild cognitive impairment in Parkinson disease: A placebo-controlled study. Mov Disord 30: 912-918, 2015.

31. Wesnes KA, McKeith IG, Ferrara R, Emre M, Del Ser T, Spano PF, Cicin-Sain A, Anand R and Spiegel R: Effects of rivastigmine on cognitive function in dementia with lewy bodies: A randomised placebo-controlled international study using the cognitive drug research computerised assessment system. Dement Geriatr Cogn Disord 13: 183-192, 2002

32. Leroi I, Overshott R, Byrne EJ, Daniel E and Burns A: Randomized controlled trial of memantine in dementia associated with Parkinson's disease. Mov Disord 24: 1217-1221, 2009.

33. Aarsland D, Ballard C, Walker Z, Bostrom F, Alves G, Kossakowski K, Leroi I, Pozo-Rodriguez F, Minthon L and Londos E: Memantine in patients with Parkinson's disease dementia or dementia with Lewy bodies: A double-blind, placebo-controlled, multicentre trial. Lancet Neurol 8: 613-618, 2009.

34. Emre M, Tsolaki M, Bonuccelli U, Destée A, Tolosa E, Kutzelnigg A, Ceballos-Baumann A, Zdravkovic S, Bladström A, Jones R and 11018 Study Investigators: Memantine for patients with Parkinson's disease dementia or dementia with Lewy bodies: A randomised, double-blind, placebo-controlled trial. Lancet Neurol 9: 969-977, 2010.

35. Stubendorff K, Larsson V, Ballard C, Minthon L, Aarsland D and Londos E: Treatment effect of memantine on survival in dementia with Lewy bodies and Parkinson's disease with dementia: A prospective study. BMJ Open 4: e005158, 2014

36. Manabe Y, Ino T, Yamanaka K and Kosaka K: Increased dosage of donepezil for the management of behavioural and psychological symptoms of dementia in dementia with Lewy bodies. Psychogeriatrics 16: 202-208, 2016.

37. Mori E, Ikeda M, Nakai K, Miyagishi H, Nakagawa M and Kosaka K: Increased plasma donepezil concentration improves cognitive function in patients with dementia with Lewy bodies: An exploratory pharmacokinetic/pharmacodynamic analysis in a phase 3 randomized controlled trial. J Neurol Sci 366: 184-190, 2016.

38. Ukai K, Fujishiro H, Iritani S and Ozaki N: Long-term efficacy of donepezil for relapse of visual hallucinations in patients with dementia with Lewy bodies. Psychogeriatrics 15: 133-137, 2015.

39. Litvinenko IV, Odinak MM, Mogil'naya VI and Emelin AY: Efficacy and safety of galantamine (reminyl) for dementia in patients with Parkinson's disease (an open controlled trial). Neurosci Behav Physiol 38: 937-945, 2008

40. Larsson V, Aarsland D, Ballard C, Minthon L and Londos E: The effect of memantine on sleep behaviour in dementia with Lewy bodies and Parkinson's disease dementia. Int J Geriatr Psychiatry 25: 1030-1038, 2010.

41. Emre M,Poewe W, De Deyn PP,Barone P, Kulisevsky J, Pourcher E, van Laar T, Storch A, Micheli F, Burn D, et al: Long-term safety of rivastigmine in parkinson disease dementia: An open-label, randomized study. Clin Neuropharmacol 37: 9-16, 2014.

42. Sherman DS, Mauser J, Nuno M and Sherzai D: The efficacy of cognitive intervention in mild cognitive impairment (MCI): A meta-analysis of outcomes on neuropsychological measures. Neuropsychol Rev 27: 440-484, 2017.

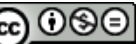

This work is licensed under a Creative Commons Attribution-NonCommercial-NoDerivatives 4.0 International (CC BY-NC-ND 4.0) License. 